Bioetectrochemustry and Bioenergetics 5, 388-400 (197S)

\title{
226 - Effect of Lewis Acids on the Electrochemical Reduction of Nicotinamide Adenine Dinucleotide *
}

\author{
by Mark A. Jexsex and Philip J. Elvisg
}

The Liniversity of Michigan, Ann Arbor, Mrichigan, 4 Srog. U.S A

Manuscript recelved January $4^{\text {th }} 1978$

Summary

Electrochemically, nicotinamide adenine dinucleotide (NAD+; DPN-; coenzyme I) is reduced in two steps, i.e., a $\mathrm{pH}$-independent one-electron reduction to the free radical, which, at more negative potential, is reduced in a one-electron, one-proton process to NADH. The variation in the electrochemical pattern resulting from interaction with two LEwIs acids known to be involved biologically with $\mathrm{NAD}^{+}$, i.e., $\mathrm{Ca}(\mathrm{II})$ and $\mathrm{Zn}(\mathrm{II})$, has been examined. Potentiometric titration indicates that $\mathrm{Ca}(\mathrm{II})$ forms a weak $\mathrm{I}$ : I complex with $\mathrm{NAD}^{+}$at $\mathrm{pH} 7.2$ (formation constant equals 38 ); d.c. polarography supports such complexation. The nature and effects of these complexes have been explored, e.g., $\mathrm{Ca}$ (II) increases the rate of charge transfer to that expected for a reversible reaction for the first reduction step only at relatively high concentration but has a marked effect on the second step even at low concentration. Zn(II) apparently forms a complex with a decomposition product of $N^{-} D^{-}$, which catalyzes the $Z_{n}$ (II) reduction.

\section{Introduction}

In recent years, the electrochemical reduction of nicotinamide adenine dinucleotide (NAD-; diphosphopyridine nucleotide; $\mathrm{DPN}^{-}$; coenzyme I), which is one of the most common respiratory coenzymes, has been extensively studied.1-6 The overall electrochemical redox behavior of the $\mathbf{N A D}+/ \mathrm{NADH}$ redox system is summarized in Fig. $\mathbf{r}^{\text {? }}$

At a potential of -0.9 to $-I . I V$, depending on the background electrolyte, $\mathrm{NAD} \mathrm{D}^{+}$is reduced in a one-electron $\left(\mathrm{r} \mathrm{e}^{-}\right) \mathrm{pH}$-independent process to a free radical, $N A \dot{D}$, which rapidly dimerizes. In the range

* Discussed at the $4^{\text {th }}$ International Symposium on Bioelectrochemistry. Woods Hole (MIass), z-8 October 1977 
of $\mathrm{pH} 7$ to 9 , the $\mathrm{I}^{-}$reduction of the free radical to $\mathrm{NADH}$ can be observed. Dimer and $\mathrm{NADH}$ can be oxidized back to $\mathrm{NAD}^{-}$at considerably more positive potential.

At present, the authors and their collaborators are attempting to obtain a more detailed picture of the electrochemical reaction pathways for the reduction of $\mathrm{NAD}^{-}$and the oxidation of $\mathrm{NADH}^{-}$One aim of such studies is clarification of the differences and similarities between the

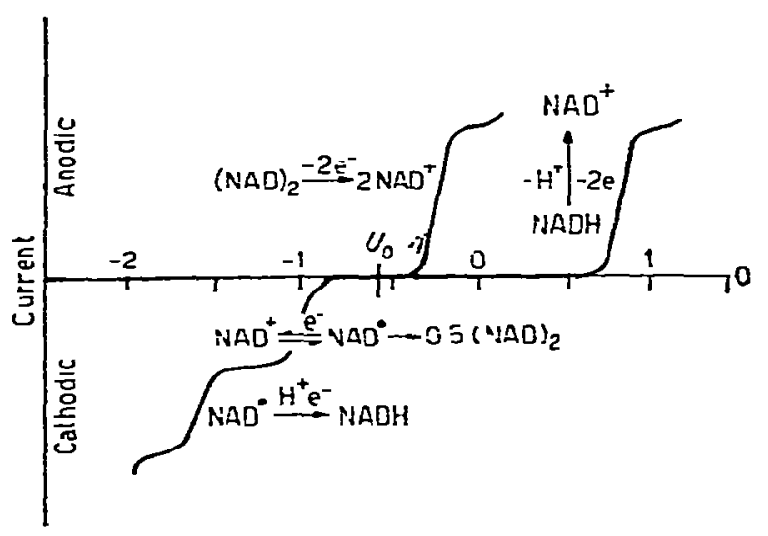

Fig I

Composite representation of the polarographic and voltammetric waves for the $\mathrm{NAD}+\mathrm{NADH}$ system in relation to the calculated formal potentral, $U_{c}{ }^{\circ}$ of $-0557 \checkmark$ for the half-reaction. $\mathrm{NAD}-+2 \mathrm{e}^{-}+\mathrm{H}^{+} \rightleftharpoons \mathrm{NADH}$, at $\mathrm{pH} 7$ and $25^{\circ} \mathrm{C}$ Potentials are vs SC.E [Reproduced with pernission from Ref 7$]$

electrochemically and biologically observed behaviors of the $N A D+N A D H$ redox system. ${ }^{7}$ The present paper reports the results of added $\mathrm{Ca}$ (II) and $Z \mathbf{n}(I I)$ on the observed electrochemical bchavior of NAD-. These two LEwIS acids were examined because of their importance in biological systems, e.g., the implication of zinc as a Lewis catalyst in liver alcohol dehydrogenase for which $\mathrm{NAD}^{-}$is the coenzyme.8-11

\section{Experimental}

\section{Chemicals}

Compounds were obtained from the following sources: nicotinamide adenine dinucleotide $\left(\mathrm{NAD}^{-}\right)$, adenosine diphosphoribose sodium salt (ADPR), and yeast alcohol dehydrogenase from P-L BrocheMrcALs and I-methylnicotinamide chloride from SigMA. Reagent grade chemicals were obtained from the following sources: tetraethylammonium chloride (TeaCl), and tetraethylammonium hydroxide (TeaOH) from Aldrich; tetraethylammonium perchlorate (Teap), zinc perchlorate, calcium perchlorate, and perchloric acid from G. FREDERICK SMITH; 2-amino-2hydroxymethyl-I,3-propanediol (Tris) from SIGMA, and other chemicals from J. T. BAKER.

Purity of $\mathrm{NAD}^{+}$was determined from enzymatic assays. ${ }^{12}$ 


\section{Apparatiss}

Polarographic and other voltammetric studies were conducted in a water jacketed one-compartment cell with a LugGIN capillary. ${ }^{13}$ For d.c. and a.c. polarography, a PAR Model 174 polarographic unit was used; for a.c. polarography (modulation voltage $=5 \mathrm{mV}$ peak; 40 and $100 \mathrm{~Hz}$ ), a PAR Model I2I lock-in amplifier/phase detector was interfaced with the Model I74. For fast-scan cyclic voltammetry, a potentiostat was used which was designed to have a minimal response time. ${ }^{13}$ Data were recorded on a Houstox INstruments Series $2000 \mathrm{x}-\mathrm{y}$ recorder and on a TEKTRONIC 5IOzN cathode ray oscilloscope equipped with suitable modules and a camera.

\section{Procedures}

Standard procedures were used. All measurements were made at $25^{\circ} \mathrm{C}$. All potentials are referred to the aqueous saturated calomel electrode (S.C.E.). The care taken with the a.c. polarographic measurements has been described. 14

\section{Initial one-electron reduction}

\section{Effect of $\mathrm{Ca}(I I)$}

I. d.e. and a.c. polarography. The d.c. and a.c. polarographic behavior of mixtures of $0 .+2 \mathrm{~m} M I \mathrm{NAD}^{-}$and $\mathrm{Ca}(\mathrm{II})(0.25$ to roo $\mathrm{m} I$ ) were studied at $\mathrm{pH} 7.2$ and 9.3 in o.I $M$ Teap and 0.0 I $M$ Tris buffer (pH was adjusted by addition of $\mathrm{HClO}_{4}$ ). The addition of $\mathrm{Ca}$ (II) had little effect on the d.c. polarographic wave until sufficient $\mathrm{Ca}$ (II) had been added to raise significantly the ionic strength of the solution. At that point, the slope of the d.c. wave became more steep, $U_{3:}$ shifted $I 5 \mathrm{mV}$ positive and the diffusion current constant, $\boldsymbol{I}_{d}$, decreased ro-I5 \% (Table I).

Essentially the same behavior was observed for the a.c. polarographic response of $\mathrm{NAD}^{+}$on $\mathrm{Ca}$ (II) addition (Table 2). At low Ca(II) concentrations, changes in the a.c. peak were slight. At 50 and $100 \mathrm{~m} M$ $\mathrm{Ca}$ (II) levels, the a.c. summit potential, $U_{s}$, was shifted 1o-25 $\mathrm{mV}$ more positive, the half-peak width decreased, and the peak became broader on the negative side of $U_{s}$; in the absence of $\mathrm{Ca}(\mathrm{II})$, the peak was broader on the positive side of $U_{s}$.

Since the presence of $\mathrm{Ca}$ (II) at the 5 o or roo $\mathrm{mM}$ level produces an a.c. polarographic response for the reduction of NAD+, which more closely approximates that predicted for a reversible charge transfer followed by an irreversible dimerization, ${ }^{15}$ it appears that the addition of $\mathrm{Ca}(\mathrm{II})$ must do at least one of the following:

(I) increase the rate of charge transfer, and/or

(2) decrease an intermolecular interaction between $\mathrm{NAD}^{+}$and its reduction products. These two alternatives can not be distinguished solely on the basis of changes in the a.c. and d.c. polarographic behavior. 
Table 1. d.c Polarographic data for the one-electron reduction of NAD in the presence of $\mathrm{Ca}\left(\mathrm{ClO}_{4}\right)_{2}{ }^{a}$

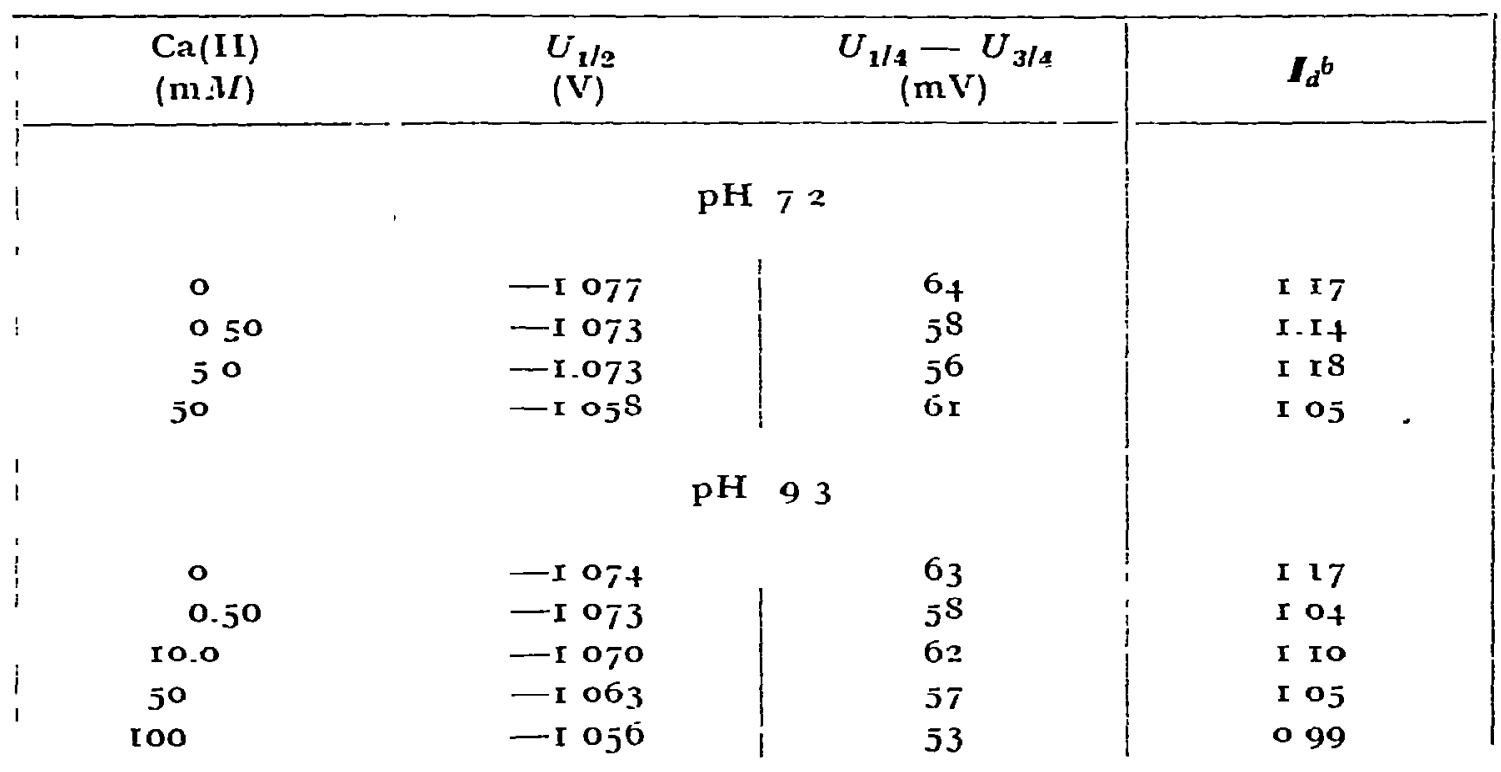

a All solutions are $0+2 \mathrm{mM} X \mathrm{AD}^{+}$in 0. ro Teap and o or $M$ Tris

$b$ Polarographic diffusion current constant $=I_{d} / \mathrm{cm}^{2 / 3} t^{1 / 6}$, calculated from average diffusion current

2. Cyclic voltammetry. The results of rapid-scan cyclic voltammetry (scan rate $v>$ roo $V / s$ ) of $N A D+$ in the presence and absence of $\mathrm{Ca}$ (II) suggest that large $\mathrm{Ca}(\mathrm{II})$ concentrations increase the rate of charge transfer.

In o I $M$ Teap with o.or $M$ Tris buffer adjusted to $\mathrm{pH} 9.3,030 \mathrm{~m} M$ NAD- shows, in the presence of $50 \mathrm{~m} M \mathrm{Ca}(\mathrm{II})$, a cathodic $U_{\mathrm{p}}$ of $-\mathrm{I}$.r. $\pm 0.005 V$, a slope of $60 \pm 5 \mathrm{mV}$ for $U_{\mathrm{p}^{\prime}}-U_{\mathrm{p}}$ of the cathodic peak, and a separation of $60 \mathrm{mV}$ between the cathodic and anodic peaks for $v=200 \mathrm{~V} / \mathrm{s}$. The slope and peak separation indicate that, for the, solution conditions specified, the rate of charge transfer is sufficiently rapid to appear reversible, i.e., $k_{s, h}$ exceeds $I \mathrm{~cm} / \mathrm{s}$, and any homogeneous reactions involv ing redox participants are being outrun. ${ }^{16}$ In the absence of $\mathrm{Ca}(\mathrm{II})$, the separation between cathodic and anodic peaks is $116 \mathrm{mV}$, which corresponds to a charge transfer rate of $0.2 \mathrm{~cm} / \mathrm{s} .{ }^{12}$

Since the dimerization involving the free radical produced on the initial $x \mathrm{e}^{-}$transfer and any interaction involving $\mathrm{NAD}^{\mathrm{T}}$ are being outrun at a scan rate of $200 \mathrm{~V} / \mathrm{s}$, the changes in voltammetric beharior caused by the action of $\mathrm{Ca}$ (II) must be due to an increase in the rate of charge transfer. This does not prove, however, that $\mathrm{Ca}$ (II) would not also affect an intermolecular interaction between $\mathrm{NAD}^{+}$and the dimer. 
Table 2. a.c. Polarographic data for the one-electron reduction of $\mathrm{NAD}^{-}$in the presence of $\mathrm{Ca}\left(\mathrm{ClO}_{4}\right)_{2}$ a

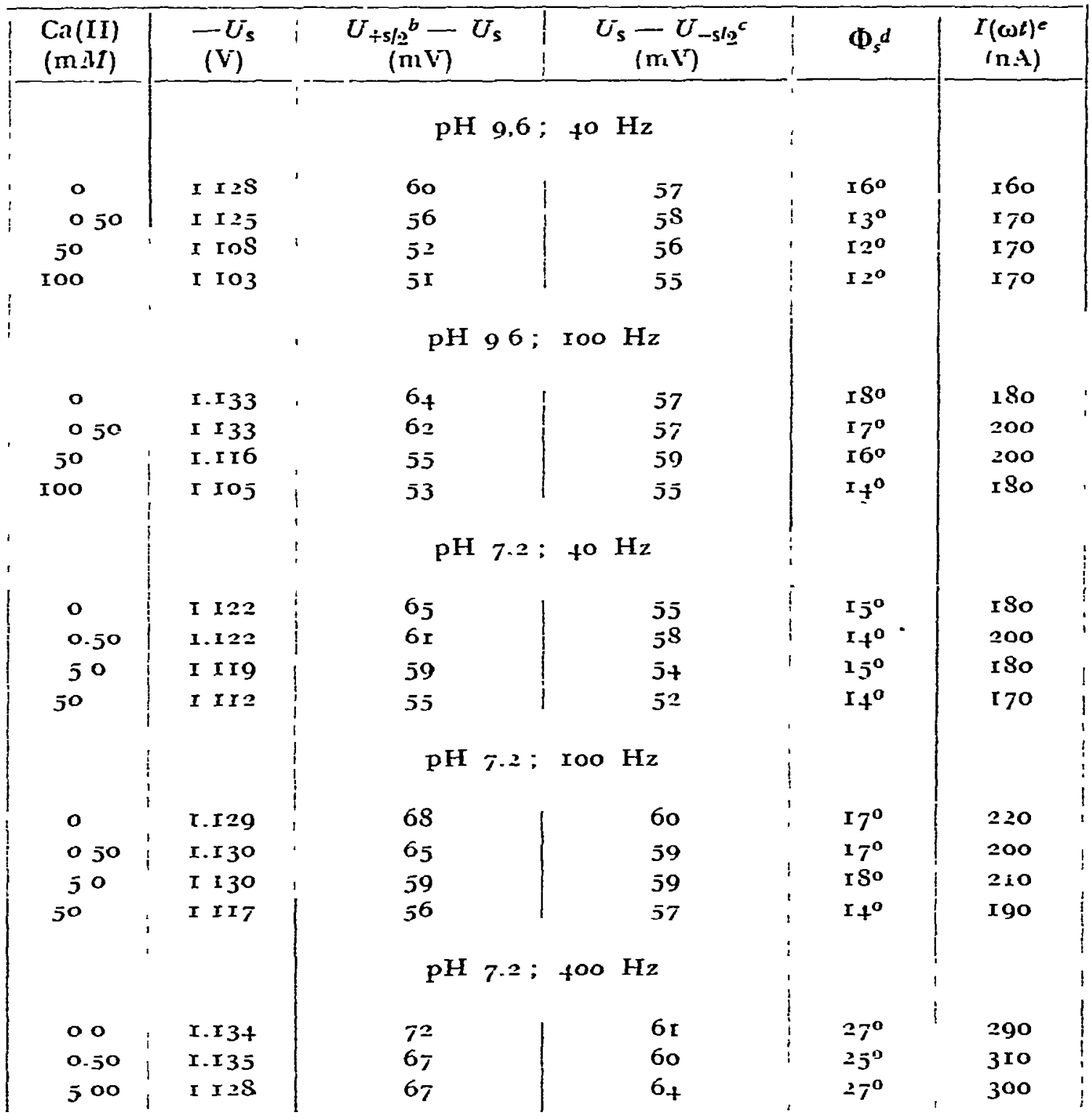

a All solutions are $0+2 \mathrm{~m} M T{ }^{2}+D^{-}$in o.Io $M I$ Teap and o.or $M I$ Tris

- Potential on the positive side of the ac. polarographic peak. where the inphase current is one-half of $I_{s}$

c Potential on the negative side of the a $c$. polarographic peak, where the inphase current is one-half of $I_{s}$.

$d$ Phase angle at the $a c$ polarographic sumnut potential

e Total faradaic current. 
Effect of $Z n(I I)$

I. d.c. and a.c. polarography. Addition of NAD+ (final concentration $=0.42$ to I $\mathrm{m} M \mathrm{Zn}(\mathrm{II})$ in 0.Io $M$ Teap and o.or $M$ Tris buffer at $\mathrm{pH}$ 7.2 produced quite striking changes in the electrochemical behavior of the $\mathrm{Zn}(\mathrm{II}) / Z n$ redox couple. In the absence of $\mathrm{NAD}^{+}, \mathrm{Zn}$ (II) showed a kinetically controlled wave with $U_{Y_{2}}=-\mathrm{r} .4 \mathrm{I} \mathrm{V}$ and a slope of $92 \mathrm{mV}$. The corresponding a.c. polarographic peak had $U_{s}-I_{.5}$ Io $\mathrm{V}$ and a half-peak width of $2.4 \mathrm{mV}$.

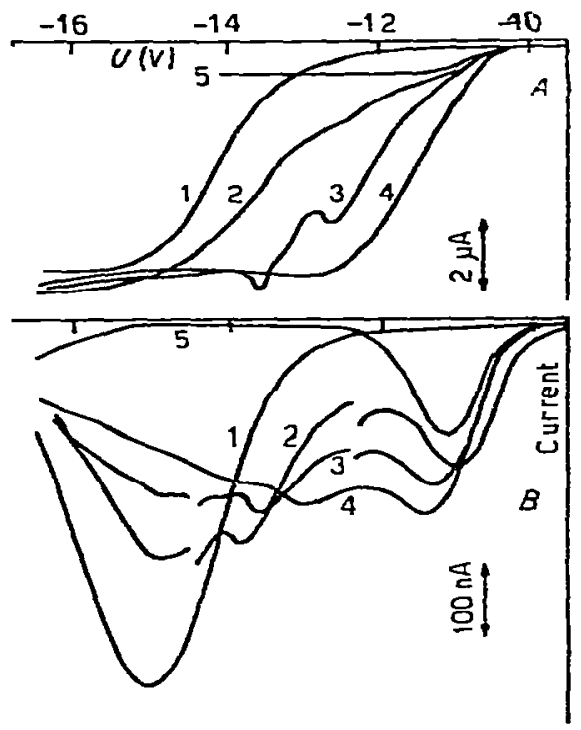

Fig 2

(A) Variation of the $d c$. polarographic behavior of mixtures of $\mathrm{Zn}(\mathbf{I I})$ and NAD+. Solution composition and nature : I, I $m M \quad Z n$ (II) in $0.10 M$ Teap and $O$ or $M F$ Tris at $\mathrm{pH} 7.2$; 2. solution $1,80 \mathrm{~mm}$ after addition of $042 \mathrm{~m} M$ NAD+; 3. solution 2. Ioo min after NAD+ addition: 4 , solution $2,245 \mathrm{~mm}$ after $\mathrm{NAD}^{+}$ addition: 5. solution 4 after $\mathrm{Zn}$ (II) was precipitated with $\mathrm{Na}_{2} \mathrm{HPO},(B)$ Variation of the $a c$ polarographic behavior (in-phase current) of mixtures of $\mathrm{Zn}$ (II) and NAD+ (controlled drop-time $=2.0 \mathrm{~s} ;$ a $c$ modulation voltage $=5 \mathrm{mV}$ peak ; frequency $=$ too $\mathrm{H}_{z}$ ). Solution composition and nature : $r, I m M$ Zn(II) in o. ro $M$ Teap and o or $M I$ Tris at $p H$ 72 ; 2 , solution 1,85 min after addition of $0.42 \mathrm{~m} M \mathrm{NAD}^{+} ; 3$, solution 2, $145 \mathrm{~min}$ after NAD+ addition: 4, solution $2,235 \mathrm{~min}$ after NAD + addition; 5, solution 4 after $\mathrm{Zn}(\mathrm{II})$ was precipitated with $\mathrm{Na}_{\mathbf{2}} \mathrm{HPO}_{\mathbf{4}}$ -

When $0.42 \mathrm{mM} \mathrm{NAD}^{+}$was added to the $\mathrm{Zn}$ (II) solution, the foot of the d.c. $\mathrm{Zn}$ (II) wave shifted positive and overlapped the $\mathrm{NAD}+$ reduction wave, whose $U_{y=}=-1.07 \mathrm{~V}$; the shift was time-dependent with an overall shift in $U_{4 / 3}$ of $260 \mathrm{mV}$ in four hours (Fig. 2). When NAD+ was first added, three waves appeared. The first came in the potential region of the $\mathrm{NAD}^{+}$reduction wave. Before this wave reached a plateau, a second wave of roughly equal height began, which also did not reach a plateau but was overlapped by a third wave which apparently was due to reduction of $Z n(I I)$. With time, the third wave shifted positive, beginning to merge with the first two waves. The second wave-began to develop into a sharp polarographic maximum about two-thirds of the way up the third wave. A second sharp maximum appeared at the top of the third wave. As the third wave continued to shift positive, the first maximum disappeared leaving behind an inflection in the third wave slope in the potential region where this maximum had previously been observed. The second maximum remained at the top of the third wave and became quite broad. When $\mathrm{Zn}(\mathrm{II})$ was then precipitated by adding $\mathrm{Na}_{2} \mathrm{HPO}_{4}$, the $\mathrm{NAD}$ - wave reappeared and was the same as 
in the absence of $\mathrm{Zn}$ (II) except for a $6 \%$ decrease in the diffusion current constant which may have been due to some hydrolytic decomposition of $\mathrm{NAD}^{+}$.

The a.c. polarographic response of the $N A D+Z n(I I)$ mixture was compatible with the d.c. polarographic behavior (Fig. 2). When NAD was added to $Z_{r_{1}}(I I)$, three peaks were formed. The first peak, corresponding to reduction of $\mathrm{NAD}^{+}$to $\mathrm{NAD}$, increased in amplitude and shifted to more negative potential with time. The $Z n$ (II) peak split into two peaks, both of which shifted positive and decreased in amplitude.

Fig. 3

(A) Variation of the $d c$ polarographic behavior of mixtures of $\mathrm{Zn}(\mathrm{II})$, ADPR and $\mathrm{I}-\mathrm{A}$ - $\mathrm{D}$ (hylnicotinamide. Solution composition and nature I. I mM Z.n(II) in o Io $M$ Teap and o or $M$ Iris at $\mathrm{pH} 7.2$ at 5 and $\mathrm{I}$ So min after the adidion of $\mathrm{Zn}(\mathrm{fI}) ; 2$ solution $r, \mathrm{I}_{5} 0$ and 195 min after the addition of $0_{5} \mathrm{~m} M$ ADPR, 3. solution 2. 45 and 120 min after the addition of $0.5 \mathrm{~m} \lambda I$ I-methylnicotinamide (B) Vanation of the $a c$. polarographic behavior (inphase current) of mixtures of $\mathrm{Zn}(\mathrm{II})$. ADPR and I-methylnicotinamide (controlled droptime $=20 \mathrm{~s} ; a c$ modulation voltage $=5 \mathrm{mV}^{-}$ peak; frequency $=100 \mathrm{~Hz}$ ). Solution compostion and nature $I$, I m.M Zn(II) in o ro .M Teap and o or $M$ Tris at $\mathrm{pH} T \geq$ at ro and $\mathrm{r}_{7} \mathrm{O}$ min after the addition of $\mathrm{Zn}(\mathrm{I} I) ; 2$, solution $I$. r6o and 200 min after the addition of $05 \mathrm{m.M}$ ADPR; 3 , solution 2 , 60 and roo min after the addition of o $5 \mathrm{~m} / \Gamma \mathrm{I}-$ methy Inicotinamide.

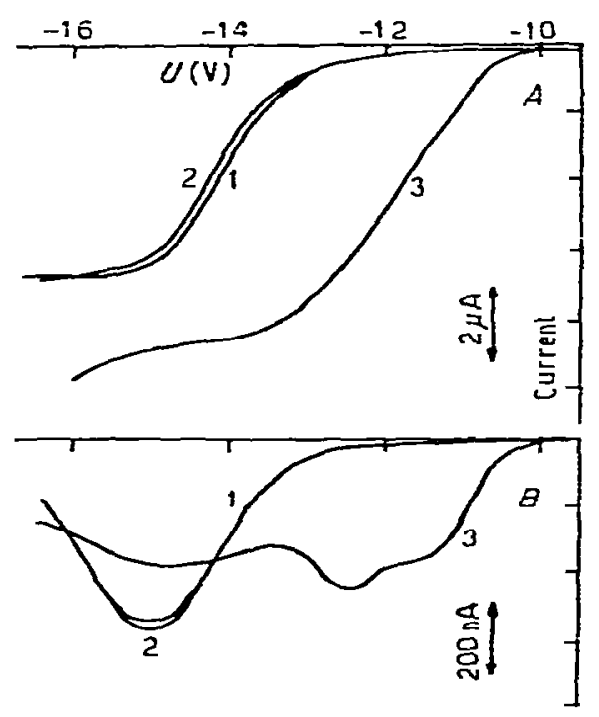

In order to determine whether $\mathrm{NAD}^{-}$was responsible for the shift in the $\mathrm{Zn}(\mathrm{II})$ wave, d.c. and a.c. polarograms were run for a solution of $\mathrm{I} \mathrm{m} M \mathrm{Zn}(\mathrm{II})$ in $0.10 \mathrm{~T}$ Teap and $0.0 \mathrm{I} M$ Tris buffer at $\mathrm{pH} 7.2$ over a 3 -hr period; no shift in $U_{y / 2}$ or $U_{s}$ was observed (Fig. 3). Sufficient adenosine diphosphoribose (ADPR) was added to the $\mathrm{Zn}$ (II) solution to give a $0.5 \mathrm{~m} M$ concentration (ADPR is similar to $\mathrm{NAD}^{+}$except that it does not contain the nicotinamide moiety). After $2.5 \mathrm{hr}, U_{y_{2}}$ for $\mathrm{Zn}$ (II) had shifted only $5 \mathrm{mV}$ negative; after over three hours, the total shift was ro $\mathrm{mV}$. Comparable shifts were observed in $U_{s}$.

At this point, sufficient $I$-methylnicotinamide was added to give a $0.5 \mathrm{~m} M I$ concentration. After $45 \mathrm{~min}$, the $\mathrm{Zn}(\mathrm{II})$ wave had shifted 2Io $\mathrm{mV}$ positive (Fig. 3). Because of this shift, the $\mathrm{I}$-methylnicotinamide wave could not be resolved. The composite wave had an $U_{1 / 2}$ of -I.I93 V and a slope of $135 \mathrm{mV}$. a.c. polarograms of the mixture run an hour after the addition of I-methylnicotinamide revealed that the $\mathrm{Zn}$ (II) peak had split into two peaks with $U_{s}$ of $-\mathrm{I} .25^{\circ}$ and $-\mathrm{I} .490 \mathrm{~V} ; U_{s}$ for Imethylnicotinamide could not be resolved because it was overlapped by 
the more positive $\mathrm{Zn}$ (II) peak. During an additional 40-min period, there was no change in the a.c. polarogram.

The behavior of the $Z n(I I) / Z n$ redox couple in the presence of ADPR and I-methylnicotinamide suggests that the nicotinamide moiety is in some fashion responsible for the $\boldsymbol{Z n}$ (II) wave pattern observed.

2. Mechanism of $Z n(I I)$-nicotinamide interaction. The fact that the shifts in $U_{y_{y}}$ occur quite slowly in the presence of $\mathrm{NAD}^{+}$and in less than $45 \mathrm{~min}$ in the presence of I-methylnicotinamide suggests two possibilities :

(a) $\mathrm{Zn}(\mathrm{II})$ complexes slowly with $\mathrm{NAD}^{+}$and more rapidly with I-methylnicotinamide. The resulting complexed $\mathrm{Zn}$ (II) either is more easily reduced or is reduced in a manner akin to the following mechanism :

$$
\begin{aligned}
\mathrm{Zn}(\mathrm{II})-\mathrm{NAD}^{-}+\mathrm{e}^{-} \rightleftharpoons \mathrm{Zn}(\mathrm{II})-\mathrm{NA} \dot{\mathrm{D}} \rightleftharpoons \mathrm{NA \dot {D }}--\mathrm{Zn}(\mathrm{I}) \underset{\text { rapid }}{\stackrel{\mathrm{e}^{-}}{\longrightarrow}} \mathrm{Zn} \\
\stackrel{\mathrm{e}}{\mathrm{e}^{-}} \longrightarrow \mathrm{ND}
\end{aligned}
$$

(b) The reduction of $\mathrm{Zn}$ (II) is catalyzed by a decomposition product of $\mathrm{NAD}^{+}$, which contains the nicotinamide moiety:

$$
\mathrm{Nic}^{+}-\mathrm{X}+\mathrm{e}^{-} \rightleftharpoons \mathrm{Nic}-\mathrm{X} \stackrel{\mathrm{Zn}(\mathrm{II})}{\longrightarrow} \mathrm{Nic}+\stackrel{\mathrm{X}}{\stackrel{\mathrm{en}(\mathrm{I})}{\stackrel{\mathrm{e}^{-}}{\mathrm{rapid}}} \mathrm{Zn}}
$$

In the case of $I$-methylnicotinamide, $X$ is the methyl group.

Since the ratio of $\mathrm{Zn}(\mathrm{II}): \mathrm{NAD}^{+}$was $5: 2$, it seems unlikely that a slow complexation with $\mathrm{NAD}^{+}$, which could at most complex only $40 \%$ of the $\mathrm{Zn}(\mathbf{I I})$, would cause the entire d.c. polarographic $\mathrm{Zn}$ (II) wave to shift. Therefore, the behavior of $\mathrm{Zn}(\mathrm{II}) / \mathrm{Zn}$ redox couple appears to be due to a catalytic reduction (equation 2) involving a decomposition product of NADr. Since the changes in the $Z n(I I)$ redox couple were not brought about by intact $\mathrm{NAD}^{+}$, this particular phenomenon was not examined further.

\section{NAD free radical reduction}

As previously indicated, the second step in the electrochemical reduction of $\mathrm{NAD}^{+}$to $\mathrm{NADH}$ involves a charge transfer to the uncharged free radical nicotinamide moiety, which produces the second polarographic wave or peak :

$$
\mathbf{N A D}++\mathbf{H}^{+}+\mathbf{e}^{-}=\mathbf{N A D H}
$$




\section{Effect of $\mathrm{Ca}(I I)$}

The reduction of $\mathrm{NA} D$ to $\mathrm{NADH}$ was examined, using d.c. and a.c. polarography on a $0.42 \mathrm{~m} M \mathrm{NAD}^{+}$solution (o.I $M$ Teap and o.or $M$ Tris at 9.3), to which 0.25 to roo $\mathrm{mMCa}$ (II) was added (Tab. 3). Cyclic voltammetry could not be used since $\mathrm{Ca}(\mathrm{II})$ shows an adsorption peak in the same potential region as the $N A D$ reduction peak.

Table 3. de Polarographic beharior of the $N \dot{A} \dot{D} / \mathrm{ADH}$ redox couple in the presence of $\mathrm{Ca}(\mathrm{II})^{a}$

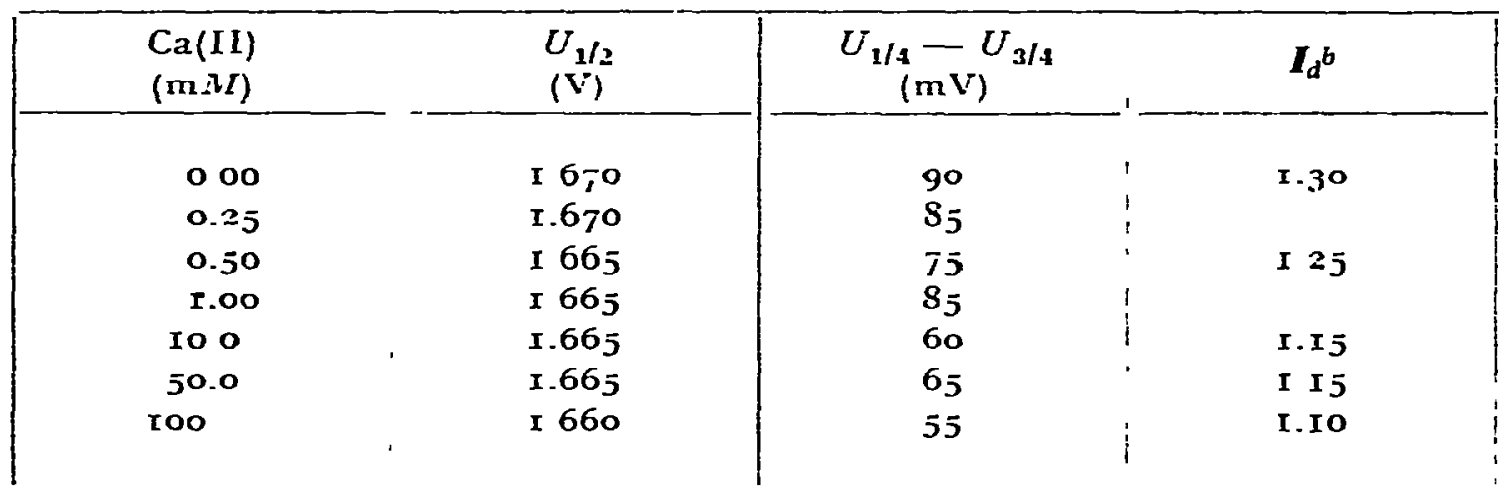

a Ail solutions are o $42 \mathrm{~m} M N^{-} \mathrm{D}^{-}$in $\mathrm{O} I M$ Teap and o or $M$ Tris at $\mathrm{pH} 93$

b Polarographic diffusion current constant, calculated from average diffusion current.

Although $U_{y_{2}}$ was relatively insensitive to $\mathrm{Ca}$ (II) addition (Tab. 3), the slope of the polarographic wave became markedly steeper with increasing $\mathrm{Ca}$ (II) concentration, e.g., $90 \mathrm{mV}$ in the absence of $\mathrm{Ca}$ (II) and $55 \mathrm{mV}$ at the Ioo $\mathrm{m} M \mathrm{Ca}$ (II) level. Addition of roo $\mathrm{m} M \mathrm{Ca}$ (II) decreased the diffusion current constant by $20 \%$.

The a.c. polarographic response of the $N A D / N A D H$ redox couple was relatively sensitive to $\mathrm{Ca}$ (II) addition $(\mathrm{Tab} .4)$. At a $\mathrm{Ca}(\mathrm{II}): \mathrm{NAD}^{\mathrm{T}}$ ratio of $1.2: \mathrm{I}$, the in-phase summit current, $I_{s}$, for the reduction of NAD had increased $35 \%$. In the presence of $100 \mathrm{mM} \mathrm{Ca(II),} \mathrm{the} \mathrm{in-}$ crease in $I_{s}$ was slightly over roo $\%, U_{s}$ shifted slightly positive, and the peak width, $\Delta U_{s / 2}$, substantially decreased.

The most viable explanation for the changes brought about by the addition of $\mathrm{Ca}$ (II), is that the presence of $\mathrm{Ca}$ (II) increases the rate of charge transfer for the reduction of $\mathrm{NAD}$. The following behavior is predicted ${ }^{18}$ for an a.c. polarographic peak for an increase in $k_{s, h}$ when the charge transfer is preceded by a reversible chemical reaction, e.g., 
Table $+a c$ polarographic behavior of the $\Sigma A \mathrm{D} / \mathrm{NADH}$ redox couple in presence of $\mathrm{Ca}(\mathrm{II}) \mathrm{a}$

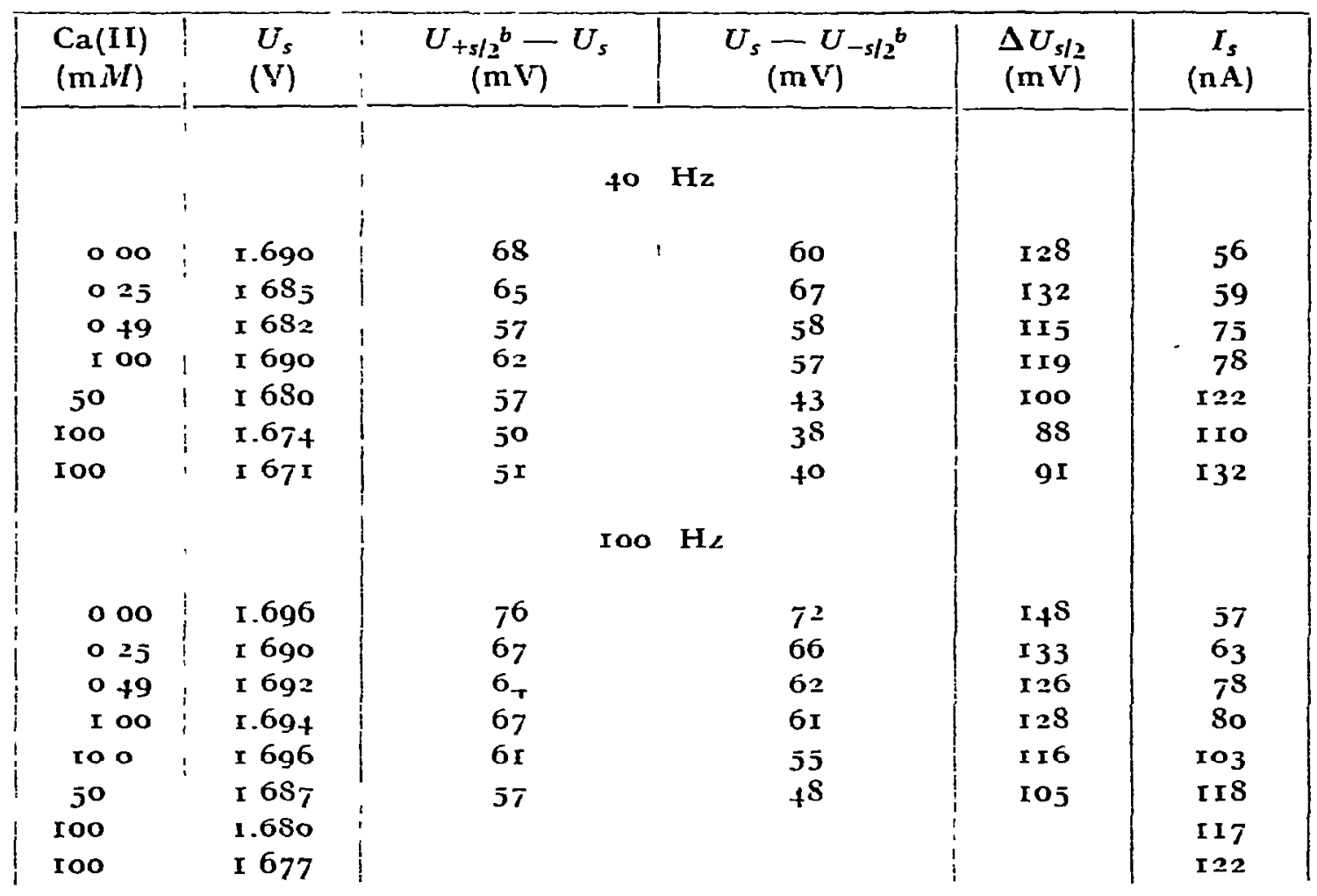

a All solutions are $042 \mathrm{~m} M N \mathrm{ND}^{-}$in o ro $M$ Teap and o oro $M$ Tris at $\mathrm{pH} 93$

$b$ Defined in footnotes $b$ and $c$ of Table 2

formation of $\mathrm{NA} \dot{\mathrm{D}}-\mathrm{HX}$, where $\mathrm{HX}$ denotes a proton donor, or of $\mathrm{NAD} \mathrm{H}^{+}$ as a preprotonation step:

(a) The in-phase a.c. current should increase.

(b) The summit potential should shift slightly positive.

(c) The negative half-summit potential, $U_{-s / 2}$, should shift substantially positive.

(d) The positive half-summit potential, $U_{+s / 2}$, should shift very little.

Examination of Table 4 shows that the addition of $\mathrm{Ca}(\mathrm{II})$ brought about the type of behavior just described. The increase in steepness of the d.c. polarographic wave (Tab. 3) on $\mathrm{Ca}(\mathrm{II})$ addition is also indicative of an increase in $k_{s, h}$. 


\section{Titration of $\mathrm{Ca}(\mathrm{II}))$ with NAD'}

Since the presence of $\mathrm{Ca}(\mathrm{II})$ modifies the electrochemical behavior of $\mathrm{NAD}^{+}, \mathrm{Ca}(\mathrm{II})$ in a $\mathrm{pH} 7.2$ o.OI $M$ Tris buffer was titrated with NADto determine to what degree $\mathrm{NAD}^{+}$would complex with $\mathrm{Ca}(\mathrm{II})$. The titration was monitored potentiometrically with a liquid-membrane ion-selective calcium electrode. Teap had to be excluded from the titration since the tetraethylammonium ion showed a significant interference with the $\mathrm{Ca}$ (II) electrode.

Table 5- Formation constant of $\mathrm{NAD}^{-}$: $\mathrm{Ca}(\mathrm{II})$ complex in o or $M$ Tris at pH 7.2

\begin{tabular}{|c|c|c|c|c|c|}
\hline 1 & $\begin{array}{c}\text { Toral } \\
{[\mathrm{Ca}(\mathrm{II})]} \\
(\mathrm{m} \mathrm{nI})\end{array}$ & $\begin{array}{c}\text { Total } \\
{\left[X^{-} \mathrm{D}^{-}\right]} \\
(\mathrm{m} . \mathrm{M})\end{array}$ & $\begin{array}{l}\text { Uncomplexed } \\
{[\mathrm{Ca}(\mathrm{II})]^{\pi}} \\
(\mathrm{m} M I)\end{array}$ & $\begin{array}{c}{[\mathrm{NAD}+\mathrm{Ca}(\mathrm{II})]} \\
(\mathrm{m} M)\end{array}$ & $\begin{array}{l}K_{f}^{b, c} \\
\left(M^{-1}\right)\end{array}$ \\
\hline \multirow{2}{*}{\multicolumn{6}{|c|}{$63 \div 19$}} \\
\hline & & o joo & & & \\
\hline \multirow[t]{2}{*}{ i } & $0.94 x$ & I. $99+$ & o 900 & $00+1$ & $40 \pm 10$ \\
\hline & o SSI & I $6 I_{5}$ & o $S \geq 3$ & 0.58 & $-45 \pm s$ \\
\hline i & $0 . \mathrm{So}_{4}$ & 2155 & o 744 & 0060 & $3^{S \pm}$ \\
\hline 1 & 0740 & 2609 & 0667 & 0073 & $+3 \pm$ \\
\hline i & o 669 & $3 \times 12$ & o 598 & $007 I$ & $39 \pm$ \\
\hline \multirow[t]{3}{*}{ i } & o 624 & $3+30$ & 0552 & 0072 & $39 \pm$ \\
\hline & o $56 I$ & 3874 & 0504 & 0.057 & $30 \pm$ \\
\hline & o $5 \mathrm{I}_{4}$ & +203 & $0+4 T$ & 0067 & $36 \pm$ \\
\hline i & $047+$ & $+4^{\mathrm{S} 2}$ & 0 to5 & $\circ 069$ & $39 \div$ \\
\hline & $0+3 t$ & $+-74^{6}$ & 0370 & 0067 & $39 \pm$ \\
\hline
\end{tabular}

a The free $\mathrm{Ca}(\mathrm{II})$ concentration was determined potentiometrically

$b$ The uncertainty In $K_{f}$ reflects an uncertainty of $\pm 0.2 \mathrm{mV}$ in the potentiometric determination of the free $\mathrm{Ca}(\mathrm{II})$ concentration

c Weighted mean based on the uncertainty in each $K_{f}$ determination $=3^{8} \mathrm{M}^{-1}$; standard deviation $= \pm+$

Since the formation constant of the Ca(II)-NAD+complex was not sufficiently large for the titration to show a clear cut end-point, it was necessary to calculate the formation constant, $K_{f}$, from the potentiometrically determined free $\mathrm{Ca}$ (II) concentration (Tab. 5). A value for $K_{f}$ of $38 \pm+M^{-1}$ (mean and standard deviation for Ir measurements) was determined for $3 \mathrm{I}: \mathrm{I}$ ratio $\mathrm{Ca}(\mathrm{II}): \mathrm{NAD}^{+}$complex.

Inasmuch as the formation constant is quite small, it seems unlikely that the complexation of $\mathrm{NAD}^{-}$with $\mathrm{Ca}(\mathrm{II})$ is entirely responsible for 
changes in the electrochemical behavior of the NAD/NADH redox couple, unless the free radical $N A \dot{D}$ reacts with $\mathrm{Ca}(\mathrm{II})$ exceedingly rapidly to form a $\mathrm{Ca}(\mathrm{II})$ : NAD complex, which has a very large $K_{f}$.

\section{Effect of $\mathbf{C a}(\mathrm{II})$ adsorption on $\boldsymbol{k}_{s, b_{2}}$}

Since the changes in the wave II polarographic behavior are substantial even at low $\mathrm{Ca}$ (II) concentration, e.g., $0.5 \mathrm{mM}$, it is unlikely that these changes are due in any large measure to an increase in ionic strength. However, adsorption of at least some $\mathrm{Ca}(\mathrm{II})$ at the electrodesolution interphase in the potential region where reduction of NAD occurs, could be responsible for the increase in the heterogeneous rate constant for the $\mathrm{NAD}$ reduction.

$\mathrm{Ca}(\mathrm{II})$ shows an a.c. polarographic peak at a potential only slightly negative of the reduction potential of the $\mathrm{NAD} / \mathrm{NADH}$ couple. The size of the peak is dependent on the $\mathrm{Ca}$ (II) concentration with the peak being sufficiently large at 50 and $100 \mathrm{mM} \mathrm{Ca}$ (II) that it begins to overlap the a.c. peak for the free radical reduction. Moreover, on cyclic voltammetry of $0 .+2 \mathrm{~m} M \mathrm{NAD}^{+}$in $0 . \mathrm{r} M$ Teap with a 0.0 I Tris buffer at $\mathrm{pH} 9.3$ and 5o $\mathrm{mM} \mathrm{Ca}(\mathrm{II})$, the adsorption peak due to $\mathrm{Ca}$ (II) completely obscures the NAD reduction peak.

The adsorption of a positively charged species such as Ca(II) at an electrode-solution interphase, which is at a potential negative to the potential of zero charge, will have the effect of reducing the apparent negative charge on the electrode. As a result, there will be less electrostatic repulsion between the electrode surface and ions of the same charge, e.g., NAD $-H X$ which has a net charge of -2 due to the presence of two singly ionized phosphate groups, and the population of negative ions at the outer HelmholTz plane will increase. With a decrease in electrostatic repulsion between NAD-HX and the electrode surface, an increase in the rate of charge transfer is quite reasonable.

\section{Acknowledgement}

The authors thank the Natronal Science Foundation, which helped support the work described. MAJ thanks the Allied CheMICAL Corporation for a fellowship.

\section{References}

B. Ke, Biochım. Biophys ftcta 20, 5+7 (r956)

$2 \mathrm{~J}$ N BuRNetT and A $\mathrm{L}$. UNDerwood, Biochemistry 4, 2060 (1965)

3 A J. Cuxingham and A L Uxderivood, Biochemistry 6, 266 (1967) 
4 K SV. Saxthasav and P.J. Elving, J. Am. Chem. Soc. 95, 5+82 (r973)

$5 \quad P$ Leduc, $D$ TheVexot and $R$ BUVet, Bioelectrochem. Bioenerg. 3 , $+9 \mathrm{r}$ $(x 9 ; 6)$

6 C.O. Schmakel, E $\mathrm{S} V$. Santhaxam and P J. Elving, $J$. $A m$ Chem Soc. 97, $50 S_{3}(1975)$

7 P J Eling, C O. Schutkel and K S V. Santhanam, Crit. Reu stnal. Chem 6, I $(1976)$

8 II F. Duxi and J.S Hutchissox, Bzochemistry 12, 4 SS2 (I973)

9 C-I. Braxdex, H. Jorxarale, H. Ekluxd and $B$ Furugrex, in The Enzymes, P.D. Boyer (Editor), Academic Press, New York (r9T5) Fol 11

$10 \mathrm{H}$ Suxd and $\mathrm{H}$ Theorell, in The Enzymes. P.D Boyer, $\mathrm{H}$ LARDy and K MIYrbick (Editors), Academic Press, New York (Ig63) Vol. 7

11 S Thisguchi, H. Theorele and A Akesor, Acta Chem Scand 21, 1903 $(\mathrm{rg}, 6)$

12 S P Colowick and X.O KaPLAN, Methods in Enzynology. Academic Press. New York (1957) Vol. 3

13 T E CcMming, ML.A Jexsex and P.J. Elvixg, Electrochim. Acla accepted for publication

14 II A Jensex, T E. Cunungs and P.J Elixg, Bioelectrochem. Bzoenerg. 4, $+7+(197 \pi)$

15 J.W. Hayes, I. Ruzic, D E Smith, G L Boomax and J R Delitastro, $J$ Electroanal Chem. Interfacial Electrochem. 51, 269 (1974)

16 R.S Nicholsox and I Shiss, final Chem 36, 706 (r96+)

17 RS Nicholsox. Anal Chem. 37, I35x (x965)

18 T.G MICCoRd and D E. Sirth, Anal. Chem 41, r r6 (rg69) 